\title{
CHARACTERIZATION OF HYDROXYPROPYL CELLULOSE PRODUCED FROM $\alpha$-CELLULOSE BETUNG BAMBOO (DENDROCALAMUS ASPER) AND IT'S APPLICATION IN TABLET FORMULATION
}

\author{
HERMAN SURYADI, HARMITA, MUHAMMAD HERPI AKBAR, PINGKAN LESTARI
}

Faculty of Pharmacy, Universitas Indonesia, Depok, 16424, Indonesia

Email: hsuryadi@farmasi.ui.ac.id

Received: 30 Nov 2018, Revised and Accepted: 09 Jan 2019

ABSTRACT

Objective: This study aimed to obtain the physicochemical properties of hydroxypropyl cellulose (HPC) powder from $\alpha$-cellulose Betung bamboo and its characteristics in tablet formulation.

Methods: HPC was prepared by hydroxypropylation of $\alpha$-cellulose using $25 \%$ (w/v) sodium hydroxide and 10 ml propylene oxide (based on 1 g $\alpha$ cellulose) at $70{ }^{\circ} \mathrm{C}$ for $3 \mathrm{~h}$. HPC of Betung bamboo (HPC BB) was characterized using fourier transform infrared (FTIR) spectrometry, particle size analyzer (PSA), x-ray diffraction (XRD), scanning electron microscope (SEM) and compared to HPC grade SL (HPC SL) as the reference. Then, HPC $\mathrm{BB}$ was used as a binder in tablet formulation by direct compression method and the resulted tablets were evaluated. The tablets evaluation including weight and size uniformity, hardness, friability and disintegration time.

Results: The results showed HPC BB powder was yellowish white, odorless and tasteless, pH 7.49, residue on ignition 0.68\%, hydroxypropoxy groups content $54.75 \%$, average particle size $37.39 \mu \mathrm{m}$, loss on drying $1.09 \%$, and moisture content $3.34 \%$. Flow properties of powder fulfilled the requirements based on literature. Infrared spectrum and diffraction pattern of HPC BB were relatively similar to HPC SL. The tablets have average weight $403.495 \mathrm{mg}$, diameter $12.16 \mathrm{~mm}$, thickness $3.11 \mathrm{~mm}$, hardness $4.11 \mathrm{KPa}$, friability $2.04 \%$ and disintegration time $24.88 \mathrm{~s}$.

Conclusion: Based on the comparison of powder characteristics and tablets evaluation, HPC BB has a great potential in tablet formulation which showed similar characteristics to reference.

Keywords: Betung bamboo, Characterization, Hydroxypropyl cellulose, Tablet

(C) 2019 The Authors. Published by Innovare Academic Sciences Pvt Ltd. This is an open access article under the CC BY license (http://creativecommons.org/licenses/by/4.0/) DOI: http://dx.doi.org/10.22159/ijap.2019v11i2.31078

\section{INTRODUCTION}

Hydroxypropyl cellulose (HPC) is one of the pharmaceutical excipients widely used in tablet formulation including as a binder, film-coating, and extended release-matrix former [1]. HPC is easily mixed with water and has a good safety for consumption. These characteristics make HPC not only used as pharmaceutical excipients but also widely used in food industries as emulsifiers and stabilizers [2].

HPC is obtained through hydroxypropylation of cellulose which comes from natural sources. Cellulose is a major component of plant cell walls and also a polymer of $\beta$-glucose with $\beta-1-4$ bonds between glucose units $[3,4]$. Raw materials of cellulose that most commonly used for industrial purposes are woods and cotton. This is because woods and cotton contained high levels of cellulose which are 40$50 \%$ and $95-99 \%$, respectively $[5,6]$. However, the use of wood as a raw material for cellulose is considered leads to massive deforestation because regeneration of woods takes a long time and its caused ecological imbalances. Therefore, an alternative source is needed to substitute the wood as a raw material of cellulose.

The hydroxypropylation of cellulose consists of two stages, cellulose alkalization stage, and etherification stage [7]. The efficiency of the hydroxypropylation is influenced by the concentration of sodium hydroxide and propylene oxide and also the temperature and reaction time. Production of HPC from olive tree branch cellulose showed that the optimal condition of hydroxypropylation was using sodium hydroxide $10 \%(\mathrm{w} / \mathrm{v}$ ) (calculated from the cellulose weight used) and propylene oxide $115 \mathrm{~g}$ (for each $100 \mathrm{~g}$ of cellulose) at 60 ${ }^{\circ} \mathrm{C}$ for $2 \mathrm{~h}$ which resulted molar substitution 0.39 [7]. Another study on the production of HPC from snake fruit kernel showed that the use of sodium hydroxide $15.2 \%(\mathrm{w} / \mathrm{v})$ and propylene oxide $3.3 \mathrm{ml}$ (for each $5 \mathrm{~g}$ of cellulose) at $51.2^{\circ} \mathrm{C}$ for $3 \mathrm{~h}$ was the optimal condition for hydroxypropylation with molar substitution 0.3 [8]. Based on these studies, it is known that the reaction conditions and source of cellulose used are related to the molar substitution of HPC obtained.
The molar substitution and source of cellulose used for the production of HPC greatly influence its physicochemical characteristics [9]. Therefore, it is important to characterize HPC powder obtained from $\alpha$-cellulose Betung bamboo which includes identification, organoleptic, molar substitution, $\mathrm{pH}$, loss on drying, residue on ignition, bulk and tapped density, compressibility index and Hausner's ratio, angle of repose, moisture content, analysis of infrared spectrum, analysis of particle size, analysis of x-ray diffraction and analysis of scanning electron microscope. Furthermore, HPC of Betung bamboo (HPC BB) was used in tablet formulation and tablet obtained was evaluated including weight uniformity, diameter, thickness, hardness, friability and disintegration time. The purposes of this study were to obtain the characteristics of HPC powder obtained from $\alpha$-cellulose Betung bamboo and tablet formulation characteristics using HPC BB. Then, it was compared with HPC grade SL (HPC SL) which commercial product that commonly used.

\section{MATERIALS AND METHODS}

\section{Instruments}

The instruments used in this study were analytical balances (Sartorius Secura), desiccator (Duran), furnaces (Cole-Parmer), hot plate and stirrer (IKA Hs-7), oven (Heraeus), platinum crucible, tablet press (Erweka EP-1), vacuum filter (Portable Diaphragm Aspirator BMX-1), waterbath (Memmert WNB 14) and other glass commonly used in the laboratory. The instruments used for analysis were bulk tapped density tester (IMF BDT M4-005/04), disintegration tester (Electrolab ED-2 SAPO), flowmeter (Erweka GDT), friability tester (Erweka TA-R), FTIR spectrophotometer (Shimadzu FTIR-8400S), hardness tester (Erweka THB 125), moisture content tester (ADAM AMB50), Particle Size Analyzer (CILAS 1190), pH meter (Eutech), Scanning Electron Microscope (QUANTA 650), UV-VIS spectrophotometer (Shimadzu UV-1601) and X-ray diffractogram (XRD Panalitycal X'Pert Pro). 


\section{Raw material}

The raw material used in this study is a Betung bamboo powder (Dendrocalamus asper) that was obtained from Badan Penelitian Tanaman Rempah dan Obat (BALITTRO), Bogor.

\section{Chemical material}

The chemicals used were acetic acid (Merck), avicel PH 101 (FMC BioPolymer), nitric acid (Merck), sulfuric acid (Merck), ethanol (Merck), HPC SL (Nippon Soda), isopropyl alcohol (Merck), methanol (Merck), potassium bromide (Merck), kollidon CL (Xi'an Harmonious Natural Bio-Tech), magnesium stearate (Merck), sodium hydroxide (Merck), sodium hypochlorite (Merck), paracetamol (Hebei Jiheng Group Pharmaceutical), propylene oxide (Sigma), propylene glycol (Merck), sodium nitrite (Merck), sodium sulfite (Merck), n-hexane (Merck) and ninhydrin (Merck).

\section{Extraction}

The bamboo powder was washed repeatedly with water, then dried in an oven at $60^{\circ} \mathrm{C}$ for $24 \mathrm{~h}$. A total of $300 \mathrm{~g}$ of bamboo powder was macerated with $3 \mathrm{l}$ of n-hexane: ethanol (2:1) for $24 \mathrm{~h}$ and stirred every $8 \mathrm{~h}$. The pulp was filtered and dried at room temperature [10].

\section{Isolation of $\alpha$-cellulose betung bamboo}

For every $300 \mathrm{~g}$ of extracted bamboo powder was mixed in $4 \mathrm{l}$ of nitric acid $3.5 \%(\mathrm{v} / \mathrm{v})$ (containing $40 \mathrm{mg}$ of sodium nitrite) and heated at $90{ }^{\circ} \mathrm{C}$ for $2 \mathrm{~h}$ on a hot plate. The insoluble part was separated by filtration and the residual obtained was washed with distilled water. The residu was mixed in $3 \mathrm{l}$ of a mixed solution containing sodium sulfite $2 \%(\mathrm{w} / \mathrm{v})$ and sodium hydroxide $2 \%$ $(\mathrm{w} / \mathrm{v})(1: 1)$ at $50^{\circ} \mathrm{C}$ for $1 \mathrm{~h}$, followed by filtration and washing. The residue was bleached by mixing it into $2 \mathrm{l}$ of a mixed solution containing sodium hypochlorite $3.5 \%(\mathrm{v} / \mathrm{v}$ ) and distilled water (1:1), then the mixture boiled for $10 \mathrm{~min}$ and continued with filtration and washing. Furthermore, the residue was mixed in $2 \mathrm{l}$ of sodium hydroxide $17.5 \%(\mathrm{w} / \mathrm{v})$ and heated at $80^{\circ} \mathrm{C}$ for $30 \mathrm{~min}$, followed by filtration and washing until the residue was clean. The residue obtained is $\alpha$-cellulose. It was dried at $60{ }^{\circ} \mathrm{C}$ and grinded to fine powder [10].

\section{Hydroxypropylation reaction of $\alpha$-cellulose betung bamboo}

For every $30 \mathrm{~g}$ of $\alpha$-cellulose powder was mixed in $600 \mathrm{ml}$ of isopropyl alcohol using magnetic stirrer. Then $120 \mathrm{ml}$ of sodium hydroxide $25 \%(\mathrm{w} / \mathrm{v})$ was added gradually to the mixture and stirred continuously at room temperature for $2 \mathrm{~h}$. The mixture was heated to $50^{\circ} \mathrm{C}$, then $300 \mathrm{ml}$ of propylene oxide was added gradually and stirred using magnetic stirrer. Beaker glass was tightly closed and heated at $70{ }^{\circ} \mathrm{C}$ for $3 \mathrm{~h}$. The mixture was cooled at room temperature, then neutralized by adding acetic acid $90 \%$ to $\mathrm{pH} 7$. Precipitation was done by adding methanol followed by washing using ethanol $80 \%$ repeatedly. The precipitate obtained is HPC. It was dried at $50{ }^{\circ} \mathrm{C}$ for $6 \mathrm{~h}$ and grinded to fine powder. The HPC powder is stored in desiccator $[7,11]$.

\section{Determination of percent hydroxypropoxy content and a molar substitution (MS)}

The percent hydroxypropoxy content and molar substitution were determined as reported in the literature [12]. This method involves hydrolysis of hydroxypropyl group to propylene glycol. The propylene glycol then dehydrated into propionaldehyde and the enolic form of allyl alcohol. After these products were reacted with ninhydrin to form purple color, the absorbance was measured using UV-VIS spectrophotometer at a wavelength of $400-415 \mathrm{~nm}$ [9].

\section{Organoleptic test and identification}

Organoleptic test and identification of HPC powder refer to the British Pharmacopoeia 2008 [13]. HPC powder was placed on the white base and the appearance, color, smell, and taste were observed. Identification was carried out by dissolving $1 \mathrm{~g} \mathrm{HPC}$ in 100 $\mathrm{ml}$ of carbon dioxide-free water and heated at $90^{\circ} \mathrm{C}$. The sample solution was cooled at room temperature. $10 \mathrm{ml}$ of this solution was transferred to the test tube and heated in the water bath. At $40{ }^{\circ} \mathrm{C}$ the solution will be foggy and become clear when cooled.

\section{pH determination}

This was done by dissolving $1 \mathrm{~g}$ of HPC powder in $100 \mathrm{ml}$ of boiling carbon dioxide-free water and stirred using magnetic stirrer. The sample solution was left at room temperature, then the $\mathrm{pH}$ of this solution was determined using $\mathrm{pH}$ meter [14].

\section{Loss on drying}

A total of $1 \mathrm{~g}$ HPC powder was transferred in a porcelain crucible, then dried in an oven at $105{ }^{\circ} \mathrm{C}$ for $4 \mathrm{~h}$. Loss on drying can be calculated by the formula:

$$
\text { Loss on drying }=\frac{(\mathrm{Wo}-\mathrm{W})-(\mathrm{Wi}-\mathrm{W})}{(\mathrm{Wo}-\mathrm{W})} \times 100 \%
$$

Where $W$ is the weight of crucible (g), Wo is the weight of crucible and sample before dried (g), and Wi is the weight of crucible and sample after dried (g) [14].

\section{Residue on ignition}

The platinum crucible was ignited in a furnace at $600{ }^{\circ} \mathrm{C}$ for $15 \mathrm{~min}$, then cooled in a desiccator and weighed. A total of $1 \mathrm{~g}$ HPC powder was weighed with the platinum crucible. Furthermore, the platinum crucible contained HPC was ignited until the ash was obtained. Ignition was carried out at $600{ }^{\circ} \mathrm{C}$ for $6 \mathrm{~h}$. After ignition was completed, platinum crucible was cooled in a desiccator and weighed. Residue on ignition can be calculated by the formula:

$$
\text { Residue on ignition }=\frac{(\mathrm{Wi}-\mathrm{Wo})}{(\mathrm{W})} \times 100 \%
$$

Where $W$ is the weight of the sample (g), Wo is the weight of platinum crucible (g), and $W i$ is the weight of platinum crucible and ash (g) [14].

\section{Bulk and tapped density}

A total of $15 \mathrm{~g} \mathrm{HPC}$ powder was transferred to a graduated cylinder and the initial volume was recorded. Graduated cylinder contained HPC powder placed on bulk tapped density tester and setting the speed to 300 taps per min. The bulk tapped density tester was turned on and final tapped volume was recorded. Bulk density and tapped density can be calculated by the formula:

$$
\text { Bulk density }=\frac{M}{V o} \text { Tapped density }=\frac{M}{V f}
$$

Where $M$ is the weight of the sample $(\mathrm{g}), V o$ is initial volume $(\mathrm{ml})$, and $V f$ is final tapped volume (ml) [15].

\section{Compressibility index and Hausner's ratio}

Compressibility index and Hausner's ratio can be calculated by the formula:

$$
\text { Compressibility index }=100 \times \frac{(\text { Vo }- \text { Vf })}{V o} \text { Hausner's ratio }=\frac{V o}{V f}
$$

Where $V o$ is initial volume $(\mathrm{ml})$ and $V f$ is final tapped volume $(\mathrm{ml})$ [15].

\section{Angle of repose}

About $15 \mathrm{~g}$ of HPC powder was poured slowly into the funnel of flowmeter until the tip of powder touched the end of the funnel. Graph paper was prepared below the funnel as a base for the fall of powder. The tip of the funnel was opened slowly, so the powder can be flowed down slowly. The height and diameter of the powder formed were measured, then the angle of repose can be calculated by the formula:

$$
\operatorname{Tan} \theta=\frac{\mathrm{h}}{0.5 \mathrm{D}}
$$

Where $\theta$ is the angle of repose $\left({ }^{\circ}\right), h$ is the height of the sample $(\mathrm{cm})$ and $D$ is the diameter of the sample $(\mathrm{cm})[16]$.

\section{Moisture content}

The moisture content of HPC powder was measured using moisture content tester ADAM AMB50 at $105^{\circ} \mathrm{C}$. A total of $1 \mathrm{~g}$ HPC powder 
was placed on the aluminum plate of moisture content tester. The device was turned on to measure the moisture content of HPC powder.

\section{Analysis of infrared spectrum}

Analysis of infrared spectrum was measured using FTIR spectrophotometer Shimadzu FTIR-8400S. About $100 \mathrm{mg}$ of $\mathrm{KBr}$ powder was weighed as blank and used to make baseline. HPC powder was weighed about $2 \mathrm{mg}$, then added $98 \mathrm{mg}$ of $\mathrm{KBr}$ powder and mixed homogeneously. The mixture was put in a disc-mold of FTIR spectrophotometer. Scanning process was performed from $4000 \mathrm{~cm}^{-1}$ to $400 \mathrm{~cm}^{-1}$.

\section{Analysis of particle size}

HPC powder was weighed about $300 \mathrm{mg}$, then dispersed in $20 \mathrm{ml}$ of distilled water. The particle size of HPC powder was measured using particle size analyzer CILAS 1190.

\section{Analysis of x-ray diffraction}

About $2 \mathrm{~g}$ of HPC powder was grinded to fine form and placed on the glass using adhesive. HPC powder was characterized using x-ray diffractogram Panalitycal X'Pert Pro MPDb to obtained diffraction pattern. It was operated in reflection mode $(40 \mathrm{kV}, 30 \mathrm{~mA})$ and used $\mathrm{Cu}-\mathrm{K} \alpha$ radiation at $2 \theta=10-90^{\circ}$.

\section{Analysis of scanning electron microscope}

HPC powder was weighed about $50 \mathrm{mg}$ and placed on stable metal palladium. Samples were cleaned with blower and coated with gold and palladium in the pressurized machine, Dionspater $1492 \times 10^{-2}$ atm. Furthermore, samples were put into a special room and irradiated with electron beam powered $10 \mathrm{kV}$. This process causes the sample to emit secondary electrons that bounce can be detected by a detector scientor and amplified by an electrical circuit that produces an image on cathode ray tube (CRT). Image shooting is done after selecting a specific part of the sample and the desired magnification in order to obtain a good and clear image [17].

\section{Tablets formulation}

Tablets were made by direct compression method. All materials were weighed according to table 1 and sifted using 20 mesh sieve. All materials were mixed homogeneously, then put the mixture into tablet compression machine Erweka EP-1 and press with mediumcompression force. The tablet formed have a weight $\pm 400 \mathrm{mg}$ with diameter $\pm 12 \mathrm{~mm}[18]$

Table 1: Formulation of the tablet using HPC SL (Formula A) and HPC BB (Formula B) [18]

\begin{tabular}{llll}
\hline Materials & Formula A & Formula B & Function \\
\hline Paracetamol (mg) & 210 & 210 & Active compound \\
Kollidon CL (mg) & 6 & 6 & Disintegrant \\
HPC SL (mg) & 13 & - & Binder \\
HPC BB (mg) & - & 13 & Binder \\
Avicel PH 101 (mg) & 169 & 169 & Filler \\
Mg stearate (mg) & 2 & 2 & Lubricant \\
\hline
\end{tabular}

\section{Weight uniformity test}

A total of 20 tablets were taken randomly from each formula, then weighed one by one and calculated the average weight. The weight of each tablet was compared with the average weight of 20 tablets, then the standard deviation was calculated.

\section{Diameter, thickness and hardness test}

A total of 20 tablets were taken randomly from each formula, then measured the diameter, thickness, and hardness of tablet using tablet hardness tester Erweka TBH 125.

\section{Friability test}

A total of 20 tablets were weighed, then the friability of tablets measured using friability tester Erweka TA-R with 100 rotations.
The tablets were removed from the device, then cleaned it's from the dust and weighed it's again. The percentage of tablets friability can be calculated by the formula [19]:

$$
\text { Friability of tablets }=\frac{\text { initial weight }- \text { final weight }}{\text { initial weight }} \times 100 \%
$$

\section{Disintegration test}

Tablet disintegration test was measured using disintegration tester Electrolab ED-2 SAPO with medium $1 \mathrm{l}$ of distilled water at $36-38{ }^{\circ} \mathrm{C}$. A total of 6 tablets were taken randomly from each formula, then each tablet put into a basket. The baskets were set to move up and down constantly 30 times per min. The endpoint of the test is indicated when there is no residue remaining in baskets.

\section{RESULTS}

Physicochemical properties of HPC

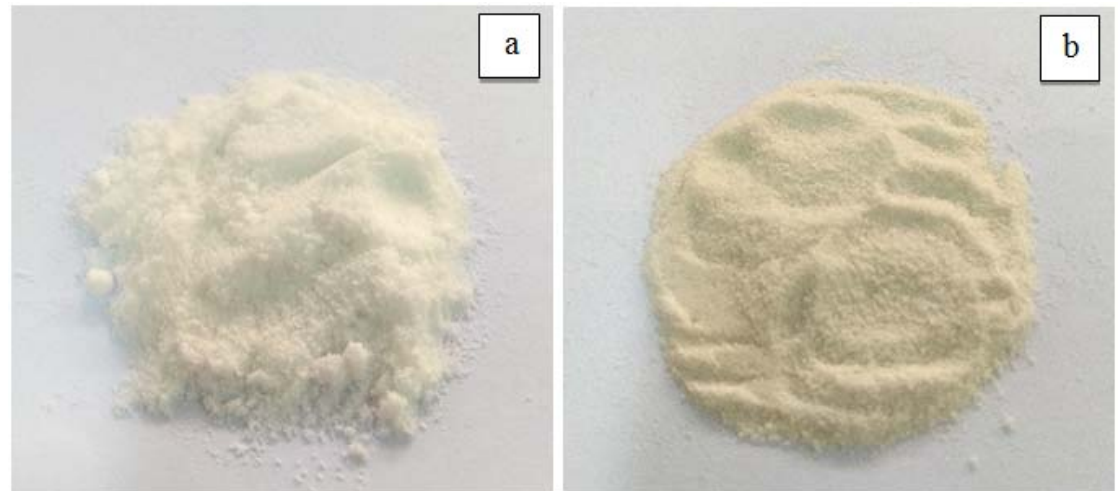

Fig. 1: HPC SL powder (a) and HPC BB powder (b) 
The results of the physicochemical properties of HPC SL and HPC BB are shown in table 2. HPC BB obtained was a yellowish white powder, odorless and tasteless (fig. 1). The test results of residue on ignition, $\mathrm{pH}$ and hydroxypropoxy groups content indicate that HPC BB fulfills the requirements of The United States Pharmacopoeia 2014 , which the residue on ignition is not more than $0.8 \%, \mathrm{pH}$ on ranges from 5.0-8.0 and hydroxypropoxy groups content on ranges from $53.4-80.5 \%$ [14]. The hydroxypropoxy groups content were determined based on the spectrophotometric analysis which produces an equation $\mathrm{y}=0.0066 \mathrm{x}+0.1746$ with linear regression coefficient $r=0.9997$. The hydroxypropoxy groups content obtained can be used to calculate the molar substitution (MS) value. The calculation results show that HPC SL and HPC BB has MS value of 7.42 and 3.32 , respectively.

\section{Powder properties of HPC}

The characteristics of HPC SL powder and HPC BB powder are shown in table 3 . Overall, the test results show that the characteristics of HPC BB powder are not significantly different from HPC SL powder.

Table 2: Physicochemical properties of HPC

\begin{tabular}{lll}
\hline Parameters & HPC SL & HPC BB \\
\hline Identification & + & + \\
pH & 6.37 & 7.49 \\
Residu on ignition (\%)a $_{\text {Assay of hydroxypropoxy groups (\%) }}^{\mathrm{a}}$ & $0.35 \pm 0.01$ & $0.68 \pm 0.02$ \\
\hline
\end{tabular}

amean \pm SD (Standard deviation), $\mathrm{n}=3$

Table 3: Powder properties of HPC

\begin{tabular}{lll}
\hline Parameters & HPC SL & HPC BB \\
\hline Bulk density $(\mathrm{g} / \mathrm{ml})$ & $0.36 \pm 0.01$ & $0.57 \pm 0.01$ \\
Tapped density $(\mathrm{g} / \mathrm{ml})$ & $0.46 \pm 0.00$ & $0.75 \pm 0.00$ \\
Flow properties: & & $35.66 \pm 0.19$ \\
Angle of repose $\left({ }^{\circ}\right)$ & $36.11 \pm 0.12$ & $1.31 \pm 0.01$ \\
Hausner's ratio & $1.28 \pm 0.02$ & $23.80 \pm 0.73$ \\
Compressibility index (\%) & $22.13 \pm 1.40$ & $1.09 \pm 0.14$ \\
Loss on drying (\%) & $1.20 \pm 0.04$ & $3.34 \pm 0.25$ \\
Moisture content (\%) & $3.64 \pm 0.39$ & \\
\hline
\end{tabular}

mean \pm SD (Standard deviation), $\mathrm{n}=3$

\section{Analysis of infrared spectrum}

The infrared spectrum of HPC SL and HPC BB are shown in fig. 2. Both spectra have relative similar shapes and show identical peaks.

\section{Analysis of particle size}

The test results of particle size of HPC BB show that $50 \%$ of particle population has a size smaller than $33.92 \mu \mathrm{m}$ and $90 \%$ of particle population has a size smaller than $73.72 \mu \mathrm{m}$ with an average of particle size $37.39 \mu \mathrm{m}$. Whereas in HPC SL, $50 \%$ of the particle population has a size smaller than $3.08 \mu \mathrm{m}$ and $90 \%$ of the particle population has a size smaller than $27.72 \mu \mathrm{m}$ with an average of particle size $1.37 \mu \mathrm{m}$.

\section{Analysis of crystal by x-ray diffraction}

Based on analysis of diffraction pattern (fig. 3), It shows that the sharp peak of HPC SL is at $2 \theta=20.38$ with an intensity 2093, while HPC BB is at $2 \theta=20.23$ with an intensity 2099 . However, the wide peak showed significantly different results. The wide peak of HPC BB is at $2 \theta=35.12$ with intensity 560 , while HPC SL is at $2 \theta=36.89$ with intensity 372 . These results can be used to calculate the degree of crystallinity based on peak intensity method. The calculation results show that the degree of crystallinity of HPC SL and HPC BB are $82.23 \%$ and $73.32 \%$, respectively [10].

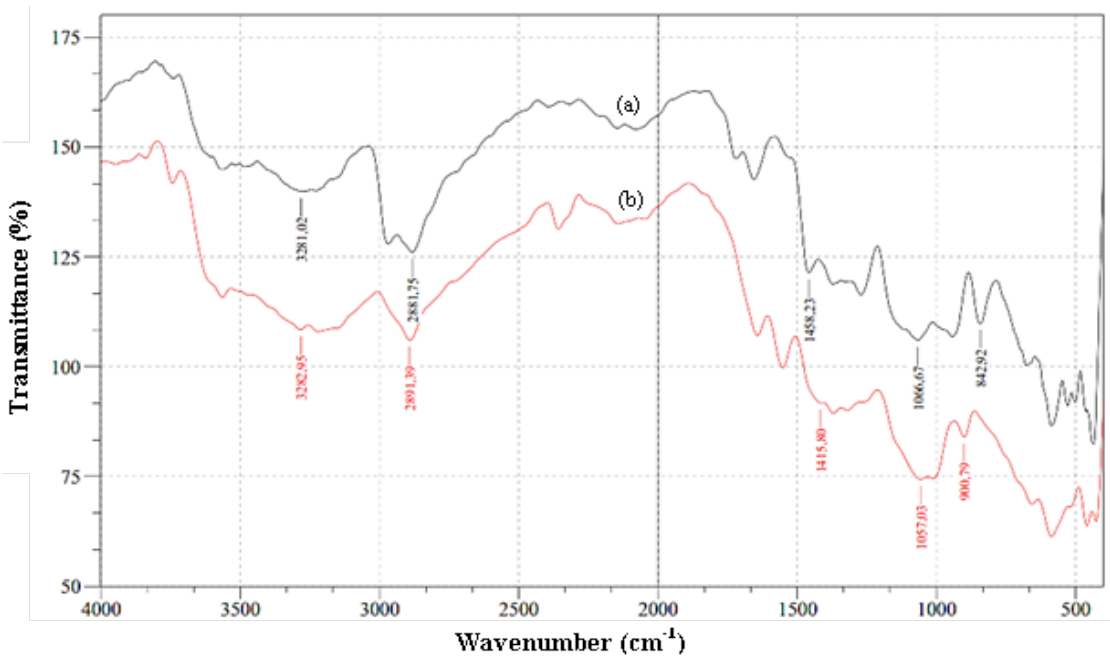

Fig. 2: Infrared spectrum of HPC SL (a) and HPC BB (b) 

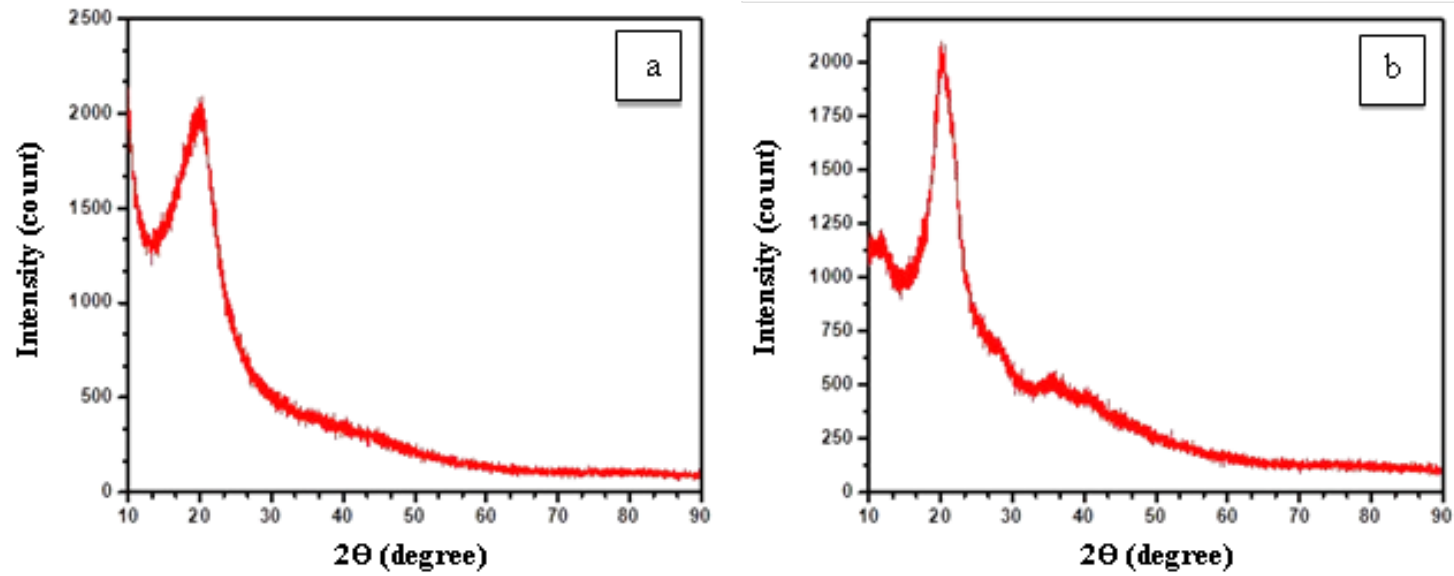

Fig. 3: Diffraction pattern of HPC SL (a) dan HPC BB (b)

\section{Analysis of morphology by scanning electron microscope (SEM)}

The test results of the scanning electron microscope of HPC SL and HPC BB are shown in fig. 4. The results indicate the differences of surface morphological between HPC BB and HPC SL. HPC BB has a rougher surface than HPC SL.

\section{Tablet characteristics}

The tablet characteristics of HPC SL and HPC BB are shown in table 4. Overall, tablet evaluation results show that the characteristics of tablets which used HPC BB as a binder are not significantly different than tablets used HPC SL as a binder.
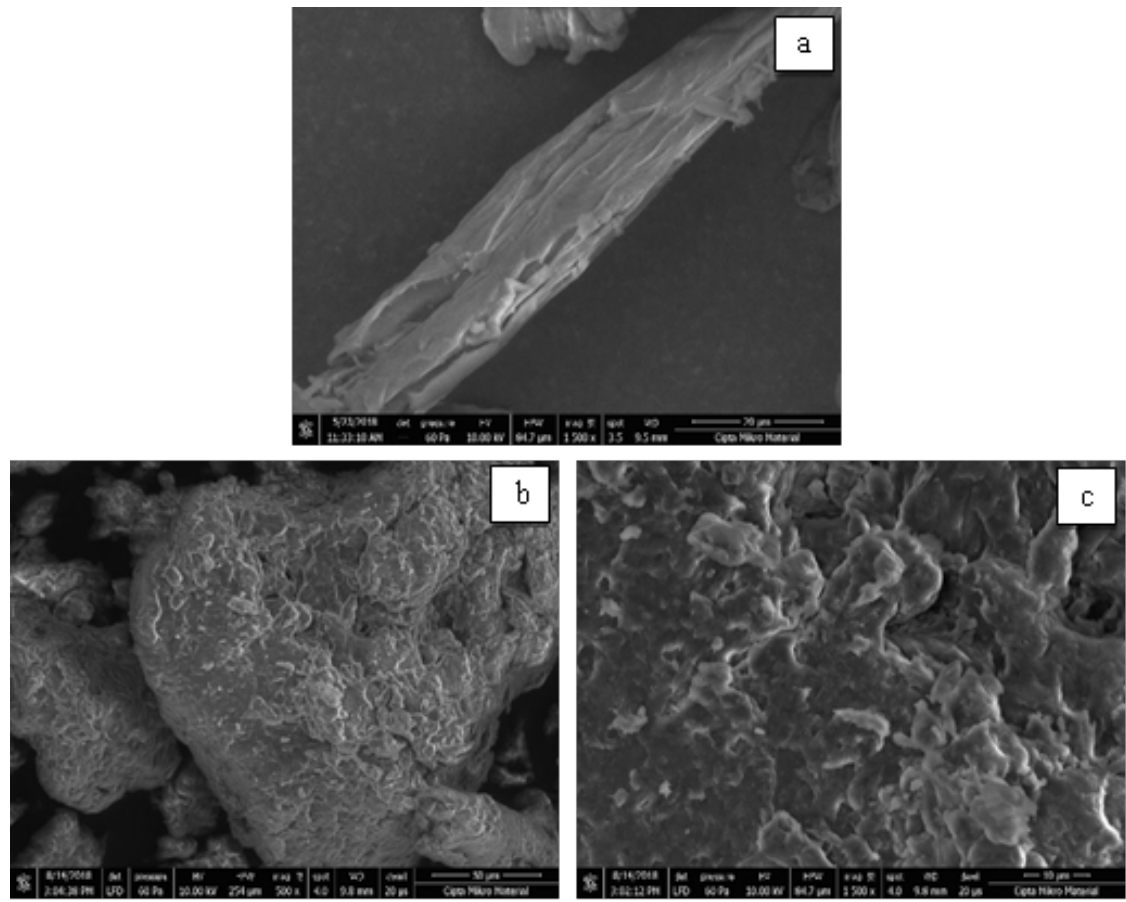

Fig. 4: Results of SEM analysis on HPC SL at M=1500x (a) and HPC BB at M=500x (b) and $M=1500 x$ (c)

Table 4: Characteristics of the tablet using HPC SL (formula A) and HPC BB (Formula B)

\begin{tabular}{lll}
\hline Parameters & Formula A & Formula B \\
\hline Weight uniformity $(\mathrm{mg})^{\mathrm{a}}$ & $398.55 \pm 9.59$ & $403.49 \pm 10.85$ \\
Size uniformity & & \\
Diameter (mm) & & $12.16 \pm 0.03$ \\
Thickness (mm) & $12.15 \pm 0.03$ & $3.11 \pm 0.04$ \\
Hardness (KPa) $^{\mathrm{a}}$ & $3.32 \pm 0.08$ & $4.11 \pm 1.06$ \\
Friability (\%) & $3.37 \pm 0.79$ & 2.04 \\
Disintegration time (s) $^{\mathrm{b}}$ & 3.37 & $24.88 \pm 3.58$ \\
\hline
\end{tabular}

amean \pm SD (Standard deviation), $\mathrm{n}=20,{ }^{\mathrm{b}}$ mean \pm SD (Standard deviation), $\mathrm{n}=6$ 


\section{DISCUSSION}

HPC produced from hydroxypropylation of $\alpha$-cellulose Betung Bamboo has a different color from HPC SL. It can be caused by several factors, including the concentration of sodium hydroxide used, the temperature of reaction, duration of reaction and washing process of the final product. The higher concentration of sodium hydroxide used, the temperature of reaction and duration of reaction will produce more yellowish HPC [11]. In contrast, more washing repetition to final product will reduce the yellowish effect caused by sodium hydroxide. The residu of ignition of HPC BB which close to the threshold of requirements indicates that it is necessary to review the washing process of the final product. This aims to obtain the best preparation method that produces high purity HPC [20]. Calculation of molar substitution shows that HPC SL has a higher molar substitution than HPC BB. Molar substitution value greatly affects solubility. HPC with molar substitution close to 4 will have better solubility in water [1].

The angle of repose, Hausner's ratio, and compressibility index are indirect methods to determine flow properties of powder [20]. Based on these parameters, it can be concluded that flow properties of HPC BB powder and HPC SL powder belong to the fair-passable category. This category is useful information in considering the use of HPC as an excipient in tablet formulation by direct compression method. Loss on drying and moisture content of HPC BB powder is not significantly different from HPC SL powder and fulfill the requirements of The United States Pharmacopoeia 2014 [14]. These results indicate that the duration and temperature of drying in the production of HPC BB was an optimal condition.

Based on data published by Sharma and Ohwoavworhua [9, 20], $\alpha$ cellulose which is the raw material for produces HPC has several typical absorption bands including the peak of $\mathrm{O}-\mathrm{H}$ stretching around $3398 \mathrm{~cm}^{-1}$, the peak of asymmetry bridge C-O-C around 1060 $\mathrm{cm}^{-1}$ and peak of $\beta$-glycosides bonding around $890 \mathrm{~cm}^{-1}$. Whereas the typical absorption bands of HPC is the peak of $\mathrm{C}-\mathrm{H}$ stretching around $2900 \mathrm{~cm}^{-1}$ which shows the symmetric stretching mode of hydroxypropyl groups [7]. The spectrum analysis shows that HPC BB has a typical absorption band of HPC at $2891 \mathrm{~cm}^{-1}$. This is evidence of the occurrence of hydroxypropylation reactions. In addition, the absorption band that can confirm the presence of hydroxypropoxy groups of HPC BB is the peak of $-\mathrm{CH}_{2}$ scissoring at $1415 \mathrm{~cm}^{-1}$.

HPC BB has a larger particle size than HPC SL. Although the differences in particle size are both significant, HPC BB still fulfills the requirement of fine powder $[1,20]$. A larger particle size of HPC BB is likely due to the simple method of powder drying and grinding. Therefore, it is necessary to review the best method of powder drying and grinding in order to obtain a particle size of HPC BB powder which closes to HPC SL powder.

Analysis of x-ray diffraction aims to determine the composition of crystalline and amorph form of HPC BB produced. The crystal form of HPC will produce sharp peaks while amorph form will produce wide peaks [10]. The results of diffraction pattern analysis show that the composition of the crystal form of HPC BB is not significantly different from HPC SL. However, the composition of amorph form shows that HPC BB is greater than HPC SL. The calculation results of the degree of crystallization by peak intensity method show that HPC BB is lower than HPC SL.

Analysis of scanning electron microscope aims to obtain surface morphology of HPC particles. The hydroxypropylation reaction in the production of HPC caused morphological changes in $\alpha$-cellulose which initially smooth surface becomes slightly rough. This is due to the deposition of propylene oxide on the surface of $\alpha$-cellulose [9]. In addition, the other factors that can be caused roughness on HPC surface are the presence of lignin in $\alpha$-cellulose Betung bamboo. This problem can be solved by optimizing the delignification process, such as increasing the duration of delignification or repeating the delignification process [10].

The characteristics of tablets obtained from formulation using HPC $\mathrm{BB}$ are not significantly different from formulation using HPC SL. All evaluation parameters show similarities in characteristics of both tablet formulations. However, the requirement of fragility parameter is not fulfilled by both tablet formulations. A good tablet formulation must have a fragility value not more than $0.8 \%[13,19]$. This is probably due to the formulation used is a standard formulation and has not been optimized. In addition, it is important to review the best tablets manufacturing methods, whether it is better to use direct compression method or wet granulation method.

\section{CONCLUSION}

HPC BB showed similar characteristics to reference on infrared spectrum, x-ray diffraction pattern, organoleptic test and powder properties. However, there were differences on $\mathrm{pH}$, residue on ignition, hydroxypropoxy group's content, the average of particle size and surface morphological to reference. The tablet which used HPC BB as a binder showed similar characteristics on all evaluation parameters compared to reference tablet.

\section{ACKNOWLEDGMENT}

The authors gratefully acknowledge to Directorate of Research and Community Service, Universitas Indonesia for financial support (Hibah PITTA) of this research.

\section{AUTHORS CONTRIBUTIONS}

All authors have contributed equally

\section{CONFLICT OF INTERESTS}

Declared none

\section{REFERENCES}

1. Rowe RC, Sheskey PJ, Quinn ME. editors. Handbook of Pharmaceutical Excipients 6th Ed. Grayslake and Washington DC: American Pharmacist Association and Pharmaceutical Press; 2009.

2. Santos EM. Final report on the safety assessment of hydroxyethyl cellulose, hydroxypropyl cellulose, methyl cellulose, hydroxypropyl methylcellulose, and cellulose gum. Int J Toxicol 1986;5:1-59.

3. Wustenberg T. Cellulose and cellulose derivatives in the food industry: Fundamentals dan Applications. Weinheim: WileyVCH; 2012.

4. Mosier N, Wyman C, Dale B, Elander R, Lee Y, Holtzapple M. Features of promising technologies for pretreatment of lignocellulosic biomass. Bioresour Technol 2005;96:673-86.

5. Chuayjuljit S, Su-Uthai S, Charuchinda S. Poly(vinyl chloride) film filled with microcrystalline cellulose prepared from cotton fabric waste: properties and biodegradability study. Waste Manage Res 2010;28:109-17.

6. Fengel D, Wegner G. Wood: Chemistry, Ultrastructure, Reaction. Berlin and New York: Walter de Gruyter; 1984.

7. Abdel Halim ES, Alanazi HH, Al-Deyab SS. Utilization of olive tree branch cellulose in the synthesis of hydroxypropyl carboxymethyl cellulose. Carbohydr Polym 2015;127:124-34.

8. Riviani E. Synthesis and characterization of hydroxypropyl cellulose (HPC) snake fruit (Salacca edulis Reinw) pondoh super kernel [Sintesis dan Karakterisasi hydroxypropyl cellulose (HPC) dari biji salak (Salacca edulis Reinw) Pondoh Super]. Thesis. Yogyakarta: Universitas Gadjah Mada; 2016.

9. Sharma R, Varshney VK, Chauhan GS. Hydroxypropylation of cellulose isolated from bamboo (Dendrocalamusstrictus) with respect to hydroxypropoxyl content and rheological behavior of the hydroxypropyl cellulose. J Appl Polym Sci 2009;113:2450-5.

10. Kharismi RRAY, Sutriyo, Suryadi H. Preparation and characterization of microcrystalline cellulose produce from betung bamboo (Dendrocalamus asper) through acid hydrolysis. J Young Pharm 2018;10:79-83.

11. Hutomo GS. Synthesis and characterization of cellulose derivate from pod husk kakao (Theobrome cacao L.)[Sintesis dan Karakterisasi Turunan Selulosa dari Pod Husk Kakao (Theobrome cacao L.)]. Dissertation. Yogyakarta: Universitas Gadjah Mada; 2012.

12. Johnson DP. Spectrophotometric determination of the hydroxypropyl group in starch ethers. J Anal Chem 1969;41:859. 
13. British Pharmacopoeia Commission. British Pharmacopoeia 2008. London: Stationery Office; 2008.

14. United States Pharmacopoeial Convention. The United States Pharmacopeia (USP) 37-NF 32. Hydroxypropyl Cellulose monograph. Rockville: The United States Pharmacopoeial Convention; 2014.

15. United States Pharmacopoeial Convention. The United States Pharmacopeia (USP) 38-NF 33. Bulk Density and Tapped Density of Powders. Rockville: The United States Pharmacopoeial Convention; 2015.

16. United States Pharmacopoeial Convention. The United States Pharmacopeia (USP) 35-NF 30. Powder Flow. Rockville: The United States Pharmacopoeial Convention; 2011.
17. Suryadi H, Sutriyo, Sari HS, Rosikhoh D. Preparation of microcrystalline cellulose from water hyacinth powder by enzymatic hydrolysis using cellulase of local isolate. J Young Pharm 2017;9:19-23.

18. Niazi SK. Handbook of pharmaceutical manufacturing formulations: compressed solid products. $2^{\text {nd }}$ Ed. New York: Informa Healthcare; 2009.

19. Kim S, Limpongsa E, Jaipakdee N. Effects of formulation parameters on properties of gastric floating tablets containing poorly soluble drug: diclofenac sodium. Int J Appl Pharm 2018;10:152-60.

20. Ohwoavworhua FO, Adelakun TA, Okhamafe AO. Processing pharmaceutical grade microcrystalline cellulose from groundnut husk: extraction methods and characterization. Int J Green Pharm 2009;3:97-104. 